\title{
O renascimento sobre o cadafalso
}

\author{
Luiz César de Sá Júnior*
}

Greenblatt, Stephen. A virada: o nascimento do mundo moderno. São Paulo: Companhia das Letras, 2012 [2011].

Partículas invisíveis e eternas chocam-se umas com as outras dando forma ao universo. Para além de qualquer plano demiúrgico, é sua constante aproximação e afastamento que engendra o sopro dos ventos, o bulir gentil ou tormentoso das águas, a trama da vida e da morte dos homens. Por vezes chamado de declinatio, inclinatio e mesmo clinamen (virada), o movimento perpétuo e aleatório da matéria, se percebido corretamente, acarretaria corolários devastadores. Afinal, ele confirmaria a inexistência de qualquer intenção divina a governar a marcha da vida, a inutilidade, e mesmo viciosa ilusão, de quaisquer religióes, e a impertinência da ideia de existência após a morte. Haveria tão somente o contínuo e natural fazer e desfazer dos átomos de que somos feitos - estes sim, imortais -, e a única busca razoável que os homens poderiam empreender seria pelo prazer.

Diante de postulados como esses, é impossível não pensar nas descobertas da física moderna e na onda de ceticismo que irrompeu no mundo contemporâneo. Contudo, o esforço de Stephen Greenblatt (autor dos consagrados Renaissance selffashioning, Shakespe- arean negotiations e Will in the world) em seu novo livro, $A$ virada: o nascimento do mundo moderno (na edição inglesa, o título escolhido foi "A virada: como o renascimento começou"), consiste precisamente em explicar ao leitor que o aparecimento da doutrina atomista remontaria a outras épocas: originalmente formulada na Antiguidade por epicuristas como Lucrécio, ela teria sido redescoberta pelo humanista Poggio Bracciolini no século $\mathrm{XV}$, passando, daí por diante, às mãos de inúmeros intelectuais.

O livro, dividido em onze capítulos que transitam sobretudo entre a época de Lucrécio e a de Poggio, não surpreende os iniciados nos estudos renascentistas, que não encontrarão nele consideraçôes gerais que tenham escapado à historiografia mais recente que, diga-se, aparece bem referenciada pelo autor no fim da obra. "A virada", contudo, tenta fazer de sua bibliografia mero ponto de apoio a projetar a moldura de seus argumentos principais, o que não se nota imediatamente; a razáo disso pode residir no fato de que o texto foi escrito em prosa bastante limpa e convidativa, algo que certamente teve peso na vitória do livro no prêmio Pulitzer de 2012 e no National Book Award de 2011. A par com esses expedientes, Greenblatt se vale de generalizaçóes, lugares-comuns e apressadas conclusóes que de modo algum fazem jus à sua brilhante carreira e à tese que

Resenha - DOI - http://dx.doi.org/10.1590/2237-101X014027015 
julgou necessário defender: a redescoberta, por Poggio, do manuscrito do célebre poema de Lucrécio, De rerum natura, teria acarretado, ainda que lenta, indireta e gradualmente, o nascimento do mundo moderno.

"A virada” tem início em janeiro de 1417, com a chegada de Poggio Bracciolini, então ex-secretário papal, a um mosteiro (o autor supóe ter sido o mosteiro de Fulda), onde ele pretendia copiar, graças à sua privilegiada caligrafia, manuscritos que fossem relevantes, particularmente aqueles ainda não identificados pelos "caçadores de livros" entre os quais se perfilava o letrado. A viagem de Bracciolini marcaria um "típico" evento na ampla marcha de ascensão do Renascimento, enquadrado por Greenblatt nos termos de uma "mudança cultural" peculiar. Não tarda para nos vermos diante da desgastada imagem do Renascimento concebido por oposição a um Medievo no qual a curiosidade, o desejo de saber e a individualidade eram reprimidos. Poggio Bracciolini desponta desde o início do livro como um humanista heroico, pronto a resgatar das trevas as letras que, alquimicamente, viriam a mudar o mundo, "virá-lo para uma nova direção" (p. 17). Ao contrapor essa virada silenciosa, propiciada pela descoberta de um manuscrito, a momentos dramáticos e "memoráveis à humanidade”, como as incendiárias disputas papais de então, Greenblatt produz um efeito de elegância a seu argumento, mas, no fundo, não faz mais do que reencenar a imagem, velha de séculos, do ressurgimento do antigo tal como construído por Petrarca. Nam fuit et fortassis erit felicius evum/In medium sordes...
Após situar o encontro inicial de Bracciolini com o De rerum natura, inicia-se uma demorada digressão acerca das fortunas do texto de Lucrécio desde seu aparecimento no mundo romano. Se, por um lado, Greenblatt acerta ao discutir as raízes da escola de pensamento que se construiu em torno de Epicuro, por outro, deixa o leitor tempo demais sem ter notícias de Poggio Bracciolini e dos desdobramentos de sua descoberta. A segunda metade do livro volta a atenção ao achado em si, sem perder de vista as polêmicas políticas, religiosas e culturais que cercavam o ambiente social de Poggio, dentre as quais se destaca a luta pelo poder papal travada por seu senhor, o então nomeado - e a seguir derrotado — “antipapa” João XXIII (Baldassare Cossa). Tendo descoberto o manuscrito, Poggio logo o enviou a outro humanista, Niccolò Niccoli, que o guardou e negou-se a reemprestá-lo a Poggio, que não havia conseguido uma cópia para si. O retrato das refregas epistolares que se seguem entre os humanistas abre espaço para Greenblatt discorrer sobre um tema essencial naquele contexto, qual seja, o das polêmicas e rivalidades letradas. Argumenta-se que, para além de toda amizade declarada por eles (que deve ser sempre lida em chave retórica), frequentemente apareciam flancos por onde penetravam diatribes que expressavam a busca da glória pessoal.

Por fim, "a virada” passa a tratar da difusão de De rerum natura, primeiro em Florença, quando começa a circular para além dos muros da biblioteca de Niccolò Niccoli, e, depois, por todo o Ocidente. Chegada a hora de demonstrar como o texto ajudou a 
"desestabilizar e a transformar o mundo" (p. 73), Greenblatt escolhe perseguir letrados renomados que de alguma forma dialogaram com o De rerum natura. Somos então apresentados à crescente presença do atomismo nas cidades italianas — seja em termos de veemente rejeição ou aceitação parcial ou disfarçada dos argumentos, que supostamente ameaçariam as bases do Cristianismo se não fossem adaptados — pelos prismas de Girolamo Savonarola, Lorenzo Valla, Marsílio Ficino, Nicolau Maquiavel e Galileu Galilei. Também despontam leituras de Lucrécio no contexto inglês, com Thomas More e Shakespeare, e no francês, com Montaigne. Por fim, como um presente ao leitor americano, Greenblatt comenta a leitura de Thomas Jefferson de De rerum natura, que fez com que este se tornasse epicurista.

Deste ponto em diante, as fragilidades do livro multiplicam-se. Faltou um estudo de fato do poema de Lucrécio, que foi tão somente resumido em um dos capítulos. Ainda que muito comentado por toda a parte, não há indícios de um esforço propriamente exegético. Um dos prejuízos que essa ausência causa é dar ao leitor a falsa impressão de que o De rerum natura é uma verdadeira ilha de modernidade a flutuar pelos mares da Antiguidade, algo que parece, a bem pensar, adequado ao argumento de Greenblatt, que jamais abandona a posição de que o De rerum natura "ajudou a dar luz à modernidade".

A inadimplência do diálogo profundo com o De rerum natura repete-se no estudo da trajetória de sua difusão, o que é particularmente grave em se tratando de uma discussão de transmissão textual. $\mathrm{O}$ diálogo com os receptores do De rerum natura foi quase sempre estabelecido de forma superficial, sem que se esclarecessem em pormenor os pontos de tensão e as imensas dificuldades em adaptar aquele complexo manuscrito ao mundo do humanismo cristão. Ademais, em certos momentos, como na descrição do consumo florentino do livro de Lucrécio, a voz de Greenblatt desaparece por trás de generalizaçóes propiciadas pela bibliografia que o escudou. Os leitores de Alison Brown, por exemplo, reconhecerão de imediato fortes ecos de The return of Lucretius to renaissance Florence por toda a parte.

Ainda nessa seara das recepçóes nos territórios italianos, admira que Greenblatt tenha se detido longamente na produção textual florentina preocupada com o manuscrito de Lucrécio, ignorando ou reduzindo ao mínimo mençôes às mais instigantes apropriaçóes do texto noutras cidades. Poderia ter se referido, por exemplo, à possível interação entre o De rerum natura e ao quadro Tempestà, do veneziano Giorgione. Tivesse dado atenção a esse caso paradigmático, no qual estava em jogo o status da poesia na formação ética do self humanista, status que permanecia sob ataque em Veneza desde 1455, com a publicação das Orationes contra poetas de Ermolao Barbaro, Greenblatt poderia ter descortinado de maneira mais frontal os grandes temas humanistas relacionados ao De rerum natura, isto é, o debate em torno da formação moral do homem, sua relação com a religião e com as dinâmicas do universo supralunar. Se eles dificilmente ajudariam a provar o nascimento da moder- 
nidade graças ao De rerum natura, teriam ao menos o benefício de serem próprios às expectativas verossímeis das práticas letradas daquele período.

$\mathrm{O}$ tema da religião permite-nos trazer à tona o ponto mais delicado de $A$ virada, isto é, a questão do ateísmo. Segundo Greenblatt, Poggio Bracciolini teria colocado em movimento um texto que punha em jogo todo o "universo mental" de seu tempo (p. 154). E, de fato, ele teria sido acusado de ateísmo. Ao acolher a leitura proposta, seríamos tentados a tomar as acusaçóes de ateísmo contra o letrado no sentido da repressão obscurantista da Igreja contra um humanista insubordinado, mas sagaz o suficiente para disfarçar sua inadequação perante aquela sociedade. Greenblatt tem razão ao salientar que, se o atomismo na Florença dos anos 1490 era digno de risos, era porque sua circulação não implicava o surgimento de depoimentos francamente a seu favor. "Nenhuma pessoa prudente", diz-nos Greenblatt, "se apresentaria e diria: 'acho que o mundo são só átomos e vazio; que, em corpo e alma, somos apenas estruturas fantasticamente complexas de átomos ligados de forma temporária uns aos outros e destinados a um dia se separar". Porém, ele não resiste ao chavão, e afirma, logo em seguida, que as ideias "subversivas e lucrecianas se infiltravam e vinham à tona toda vez que a imaginação renascentista estava em seus momentos mais vivos e intensos" (p. 186).

A insistência de Greenblatt no caráter modernamente subversivo dos humanistas quatrocentistas simplifica corrosivamente o intrincadíssimo problema da relação en- tre paganismo e cristianismo, entre cultura greco-latina e cultura bíblica. $\mathrm{O}$ ateísmo, como Greenblatt afirmara em texto muito conhecido (Invisible bullets), era um notório dispositivo de alteridade, algo sempre associado ao outro, e dificilmente poderia ser lido em perspeciva revolucionária nas cidades italianas de então. Quando Greenblatt situa a polêmica entre Poggio Bracciolini e Lorenzo Valla, e quando afirma que Poggio acusara Valla de heresia por seguir de perto Epicuro, o mestre de Lucrécio, o que deveria ter esclarecido é que se colocava em marcha um estratagema retórico cuja finalidade era a dissolução da autoridade de Valla por meio de sua aproximação a um texto de conteúdos nefastos. Tratava-se, em suma, da geração de um efeito - capaz, sim, de mobilizar afetos —, e não de uma efetiva implicação de que Valla estivesse psicologicamente afeito aos argumentos de De rerum natura.

$\mathrm{O}$ tema volta à tona quando Greenblatt discute as deliberaçóes jesuítas em contrário às doutrinas atomistas. Estamos na Roma do século XVII e no tempo de Galileu. Os átomos, cuja existência ficou garantida na Idade Média por arranjos que os deixavam na palma da Providência divina, teriam sido transformados pelo contato entre as proposiçóes de Lucrécio e a mente implacável de Galileu. Ao menos aqui, Greenblatt tem razão ao apontar a veemente reação católica a essa possibilidade, uma vez que ela prejudicava a doutrina da transubstanciação. Afinal, se o pão e o vinho consagrados a Cristo fossem substancialmente compostos de ínfimas partículas idênticas àquelas percebidas pelos homens (isto é, as acidentais, sabor, paladar 
e odor), entáo náo se apresentaria neles, em momento algum, a verdadeira carne de Cristo, o que contrariava o segundo cânone da décima terceira sessão tridentina e emanciparia uma teoria que inaugurava um segundo front de críticas aos católicos. O relato de Greenblatt encontra amparo nas sólidas teses de Pietro Redondi em Galileu herético. Contudo, resvala na ideia de uma fratura flagrada no iminente declínio do dogmatismo católico e na ascensão do racionalismo moderno encarnado em Galileu ao apropriar-se de uma "arma intelectual de destruição de massa” (p. 212). Sem entrar no mérito da difusão das ideias atomistas em largas dimensóes, é importante frisar que essa concepção de um racionalismo teleológica e dialeticamente vitorioso a partir de uma impostura individual surgida no coração da Europa católica, se bem que pertinente na lógica de $A$ virada, não traduz satisfatoriamente o espírito do livro de Redondi, e encontraria resistência em intelectuais ocupados com a história da ciência como Isabelle Stengers, Max Altman, Bruno Latour e Peter Galison.

Ainda que a reação a Galileu tenha efetivamente se dado no campo da percepção do perigo do atomismo em Il saggiatore (1623) e no Dialogo sopra i due massimi sistemi (1632), é preciso distingui-la bem de outras formas possíveis de convívio com textos pagãos. Antes do acirramento das posiçóes deflagrado por Trento, pode-se dizer que textos como De rerum natura tinham ampla circulação mesmo dentro da Igreja. Adriano Prosperi demonstra, em artigo incluído na coletânea A cultura do romance, organizada por Franco Moretti, que a aliança entre homens for- mados pelas letras greco-latinas e Igreja era por vezes táo forte que o Index de 1549 fora organizado por ninguém menos que o Monsignor della Casa Ludovico Becaelli, letrado amigo de Pietro Bembo, um dos maiores ciceronianos da Itália e, não é de se espantar, cardeal. Naquele período, o comissário geral do Santo Ofício, Michele Ghislieri, afirmava ser ridículo ("provocaríamos o riso") censurar livros como Orlando, pois tratariam de matérias nas quais ninguém acreditava, fábulas lidas como "se leem ainda muitos livros de gentios como Luciano, Lucrécio e outros que tais".

Ora, poemas como o De rerum natura não necessariamente despertariam reações virulentas de contestação à Igreja (ainda que este tenha de fato sido condenado no século XVI, durante o V Concílio de Latrão), e isto porque eles eram muitas vezes tidos por fábulas, fragmentos de um passado estranho e distante, e que atraíam a curiosidade por outras razões, como sua linguagem. Greenblatt chama a atenção para isso quando diz que uma das reaçóes iniciais ao De rerum natura foi "separar o estilo poético de Lucrécio às suas ideias" (p. 187). Entretanto, ele preferiu enfatizar que os anseios de que qualquer apoio aos princípios filosóficos do texto haveriam de ser atrelados à condição herética (fora de seu lugar historicamente mais apropriado, qual seja, na reação jesuíta do século XVII), menosprezando algo táo ou mais relevante, a saber, o apreço efetivo que letrados como Lorenzo Valla e o próprio Braccilioni tinham pelo estilo de textos antigos. No mesmo período em que essas discussóes ocorriam começava a chamada "controvér- 
sia ciceroniana", no interior da qual letrados italianos debatiam se o estilo de sua escrita deveria derivar de um único autor ou se a melhor escrita se formaria a partir de um consumo e digestão ecléticos dos melhores prosadores e poetas latinos. Greenblatt a nada disso prestou atenção.

Roger Chartier lembrou, em livro recente, que Greenblatt foi o responsável por organizar, com o dramaturgo Charles Mee, uma reencenação (na verdade, uma recriação) da peça Cardenio, cujo roteiro original se perdera a partir de suas primeiras apresentaçóes, em 1612 e 1613. Cardenio era importante por ser uma peça que comprovava a penetração da obra de Cervantes na Inglaterra e sua possível apropriação por Shakespeare, que poderia ter sido um de seus autores. Mas não era fácil - nem nos séculos precedentes nem agora - representar uma peça que não existe mais, e a trajetória das diversas tentativas (até a de Greenblatt e Mee) foi o centro das atençóes do livro de Chartier, Cardenio entre Cervantes e Shakespeare, história de uma peça perdida.

Essa história remete a um aspecto da Época Moderna por vezes ofuscado sob o conceito positivo de "Renascimento" comemorado em $A$ virada, qual seja, o longo processo de constatação do desaparecimento de textos greco latinos, estudado, dentre outros, por Luciano Canfora, e que serviu de ponto de partida para a investigação de Chartier. O objetivo de Greenblatt e Mee era propor "um exemplo de 'mobilidade cultural', definida por Greenblatt, como 'o que ocorre quando alguma coisa é deslocada de um lugar para outro, de uma cultura para outra, ou de um espírito para outro"”. Suas afirmaçóes abrem espaço para tentarmos compreender $A$ virada em uma chave que ultrapassasse simplesmente a associação das deficiências do livro ao impulso vulgarizador de um intelectual no entanto muito sofisticado. Talvez as escolhas de Greenblatt tenham igualmente a ver com a atual agenda do "novo historicismo".

Dois anos antes de editar A virada, Greenblatt organizou um livro chamado Cultural mobility: a manifesto (Cambridge Press). Nas conclusóes, ele enumerou uma série de itens que descreveriam um roteiro adequado para estudos de mobilidade cultural. Ei-lo: a mobilidade deve ser tomada em sentido literal; a mobilidade deveria iluminar movimentos facilmente detectáveis e aqueles ocultos, procurando relaçóes concretas entre livros, ideias e pessoas; estudos de mobilidade cultural fariam bem em classificar "zonas de contato" onde os bens culturais pudessem ser negociados e seus respectivos agentes aduaneiros (tradutores, editores, censores etc.); eles também deveriam se esforçar por criar novas formas de descrever as tensóes entre agência individual e pressóes estruturais; por fim, deveriam analisar os canais de enraizamento das práticas e dos valores culturais, circuitos indispensáveis para a ocorrência de mobilidade.

Fica-se com a impressão de que se adotou uma forma pálida desse modelo em $A$ virada, razão pela qual Greenblatt procurou seguir conexóes concretas entre personagens 
individuais, também o motivo de ter estabelecido espaços nos quais o De rerum natura teria sua circulação facilitada ou impedida, ou no o sentido do elogio que fez do caráter absolutamente imprevisível e contingencial da descoberta de Poggio. Se o projeto é instigante por se esforçar em abrir novos caminhos para métodos e práticas de larga aplicação na historiografia do Renascimento (perseguir conexões concretas entre indivíduos era, afinal, o projeto de Jacob Burckhardt e seu legado), não se pode, apesar disso, deixar de criticar o empreendimento de $A$ virada, qual seja, fazer ressurgir coisas antigas por meio de pálidos efeitos de presença, presentificar o passado por meio da geração de efeitos de simpatia a alguns personagens "à frente de seu tempo" e ao próprio Greenblatt, convertido em Poggio contemporâneo, redescobridor do renascimento e da modernidade.

É certo que não há melhor espaço para tanto do que "O Renascimento". Mas qualquer esforço que queira tornar a história viva não poderá se esquecer de que o passado continua, apesar de nossos melhores esforços, distante de nós, e que seus regimes, práticas e poéticas só podem ser lidos em seu estranhamento. A despeito do calor das ideias, nenhuma virada pode mudar o fato de que ainda estamos diante dos frios corpos dos mortos.

* Doutorando em história social da Universidade Federal do Rio de Janeiro. E-mail: luizdesajunior@ gmail.com. Gostaria de agradecer a Felipe Charbel e a Andrea Daher por terem lido e comentado versóes prévias desta resenha. 